(c) American Dairy Science Association, 2005.

\title{
Compositional Factors Associated with Calcium Lactate Crystallization in Smoked Cheddar Cheese
}

\author{
P. Rajbhandari and P. S. Kindstedt \\ Department of Nutrition and Food Sciences, University of Vermont, Burlington 05405-0044
}

\section{ABSTRACT}

Previous researchers have observed that surface crystals of calcium lactate sometimes develop on some Cheddar cheese samples but not on other samples produced from the same vat of milk. The causes of withinvat variation in crystallization behavior have not been identified. This study compared the compositions of naturally smoked Cheddar cheese samples that contained surface crystals with those of samples originating from the same vat that were crystal-free. Six pairs of retail samples (crystallized and noncrystallized) produced at the same cheese plant on different days were obtained from a commercial source. Cheese samples were 5 to 6 mo old at the time of collection. They were then stored for an additional 5 to $13 \mathrm{mo}$ at $4^{\circ} \mathrm{C}$ to ensure that the noncrystallized samples remained crystal-free. Then, the crystalline material was removed and collected from the surfaces of crystallized samples, weighed, and analyzed for total lactic acid, $\mathrm{L}(+)$ and $\mathrm{D}(-)$ lactic acid, $\mathrm{Ca}$, $\mathrm{P}, \mathrm{NaCl}$, moisture, and crude protein. Crystallized and noncrystallized samples were then sectioned into 3 concentric subsamples ( 0 to $5 \mathrm{~mm}, 6$ to $10 \mathrm{~mm}$, and greater than $10 \mathrm{~mm}$ depth from the surface) and analyzed for moisture, $\mathrm{NaCl}$, titratable acidity, $\mathrm{L}(+)$ and $\mathrm{D}(-)$ lactic acid, $\mathrm{pH}$, and total and water-soluble calcium. The data were analyzed by ANOVA according to a repeated measures design with 2 within-subjects variables. The crystalline material contained $52.1 \%$ lactate, $8.1 \% \mathrm{Ca}$, $0.17 \% \mathrm{P}, 28.5 \%$ water, and $8.9 \%$ crude protein on average. Both crystallized and noncrystallized cheese samples contained significant gradients of decreasing moisture from center to surface. Compared with noncrystallized samples, crystallized samples possessed significantly higher moisture, titratable acidity, $\mathrm{L}(+)$ lactate, and water soluble calcium, and significantly lower $\mathrm{pH}$ and $\mathrm{NaCl}$ content. The data suggest that formation of calcium lactate crystals may have been influenced by within-vat variation in salting efficacy in the

Received June 1, 2005.

Accepted July 7, 2005.

Corresponding author: Paul S. Kindstedt; e-mail: paul.kindstedt @uvm.edu. following manner. Lower salt uptake by some of the cheese curd during salting may have created pockets of higher moisture and thus higher lactose within the final cheese. When cut into retail-sized chunks, the lower salt, higher moisture samples contained more lactic acid and thus lower cheese $\mathrm{pH}$, which shifted calcium from the insoluble to the soluble state. Lactate and soluble calcium contents in these samples became further elevated at the cheese surface because of dehydration during smoking, possibly triggering the formation of calcium lactate crystals.

(Key words: Cheddar cheese, calcium lactate, crystal)

Abbreviation key: $\mathbf{T A}=$ titratable acidity, $\mathbf{W S C}=$ water-soluble calcium.

\section{INTRODUCTION}

White crystalline deposits that sometimes form on the surface of Cheddar cheese have been identified as calcium lactate crystals, specifically calcium lactate pentahydrate $\mathrm{Ca}\left(\mathrm{CH}_{3} \mathrm{CHOHCOO}\right)_{2} \cdot 5 \mathrm{H}_{2} \mathrm{O}$ (Tuckey et al., 1938; McDowall and McDowell, 1939; Shock et al., 1948; Farrer and Hollberg, 1960). These crystals are assumed to form when calcium and lactate ions exceed their solubility, supersaturate the serum phase of the cheese, and then crystallize at nucleation sites. A continuous migration of calcium and lactate ions to the nucleation sites then cause the sites to grow and eventually become macro crystals (Dybing et al., 1988; Swearingen et al., 2004). The white crystals that form preferentially at the cheese surface are considered quality defects because consumers often confuse them for mold or other spoilage (Chou et al., 2003). Consumer rejection of crystallized cheeses not only results in direct financial loss to the manufacturer but also compromises the manufacturer's reputation for quality in the marketplace (Washam et al., 1982; Swearingen et al., 2004).

Several factors have been shown to favor crystallization including high lactose levels in milk (Pearce et al., 1973); milk concentrated by ultrafiltration without diafiltration (Sutherland and Jameson, 1981); certain starter culture strains (Swearingen et al., 2004); biofilm formation, and contamination of cheese by nonstarter lactic acid bacteria that are able to racemize $\mathrm{L}(+)$ lactate 
to $\mathrm{D}(-)$ lactate (Thomas and Crow, 1983; Johnson et al., 1990a; Somers et al., 2001; Chou et al., 2003); low storage temperature $\left(4.4^{\circ} \mathrm{C}\right.$ ) and loose packaging (Johnson et al., 1990b); and low salt-in-moisture levels (Swearingen et al., 2004). In addition, naturally smoked cheeses may be prone to increased crystallization due to surface dehydration that occurs during the smoking process. For example, Washam et al. (1985) concluded that dehydration during smoking triggered the crystallization of emulsifying salts at the surface of naturally smoked processed Swiss cheese. Naturally smoked Cheddar cheese is an important value-added niche product. Presumably, naturally smoked Cheddar is subjected to increased susceptibility to calcium lactate crystallization due to surface dehydration.

Some researchers have reported wide variations in crystallization behavior among retail-sized samples of Cheddar cheese that were produced from the same vat of milk, ranging from no crystals present to heavy crystal coverage (Dybing et al., 1988; Swearingen et al., 2004). The authors have observed similar variation among samples of smoked Cheddar cheese produced from the same vat. The factors responsible for withinvat variation in crystallization behavior are not well understood. Dybing et al. (1988) found no significant differences in the chemical composition or level of nonstarter lactic acid bacteria of crystallized and noncrystallized cheeses produced from the same vat. However, these authors did not measure the $\mathrm{pH}$, lactate $[\mathrm{L}(+)$ and $\mathrm{D}(-)$ ], or water-soluble calcium (WSC) content of the cheese samples, which are critical parameters that affect calcium lactate crystallization (Johnson et al., 1990b; Kubantseva et al., 2004; Swearingen et al., 2004). The objective of the present study was to compare the chemical compositions of crystallized and noncrystallized samples of smoked Cheddar cheese produced from the same vat of milk, with particular emphasis on $\mathrm{pH}$ and titratable acidity (TA), $\mathrm{L}(+)$ and $\mathrm{D}(-)$ lactate, and total calcium and WSC contents.

\section{MATERIALS AND METHODS}

\section{Sample Preparation}

Six pairs of vacuum-packaged random weight $(\sim 300$ g) retail samples of naturally smoked Cheddar cheese were obtained from local supermarkets. All cheese samples were produced at the same cheese plant, and their dates of manufacture were determined from information supplied by the manufacturer. The cheeses were produced by a milled curd procedure using an automated production line that included enclosed vats (22,727-kg capacity) for coagulating the milk and cooking the curd; an enclosed conveyor series for continuous curd dewheying, cheddaring, and milling; enclosed me- chanical metering of dry salt and automated stirring of salted curd; and block-forming towers that produced 19.1-kg blocks. The blocks were vacuum-packaged and aged for 2 to 4 mo before being cut into random-weight chunks for smoking.

The dimensions of a typical cheese sample were approximately $47 \times 60 \times 100 \mathrm{~mm}$. Each of the 6 pairs contained one crystallized and one noncrystallized sample that were produced on the same day from the same vat of milk. The 6 pairs of samples were produced on different days. The samples ranged from 5 to 6 mo of age from the date of manufacture upon collection, following which they were stored for an additional 5 to $13 \mathrm{mo}$ at $4^{\circ} \mathrm{C}$ to ensure that the noncrystallized samples remained crystal-free under normal refrigerated storage conditions. Upon completion of the storage period, the wrapping film was removed from the crystallized cheese samples, and the crystals were dislodged and collected from all 6 surfaces of each sample using a sharp blade (1991 Trimming knife blade, New Britain, CT). The scraping was done carefully and quickly to avoid temperature fluctuation and to minimize the inclusion of cheese matter with the crystalline material. The collected crystalline material was immediately weighed and then stored in tightly sealed Whirl-Pak bags (Nasco, Fort Atkinson, WI) at $4^{\circ} \mathrm{C}$ until analysis.

The crystallized (scraped) and noncrystallized cheese samples were then sectioned into 3 concentric subsamples, representing 3 different depths from each of the 6 surfaces ( 0 to $5 \mathrm{~mm}, 6$ to $10 \mathrm{~mm}$, and greater than $10 \mathrm{~mm}$ ). Each of the 3 subsamples was finely grated using a blender (Osterizer, Oster Corp., Milwaukee, WI), and then stored in tightly sealed Whirl-Pak bags (Nasco) at $4^{\circ} \mathrm{C}$ until analysis.

\section{Chemical Analysis}

Cheese subsamples were analyzed in duplicate as follows. Moisture content was determined by drying in a forced-draft oven at $100^{\circ} \mathrm{C}$ for $24 \mathrm{~h}$. Calcium and $\mathrm{Na}$ contents were determined by inductively coupled plasma atomic emission spectrometry. Salt was calculated directly from the $\mathrm{Na}$ content. Water-soluble calcium was determined using the extraction method described by Metzger et al. (2001). Cheese $\mathrm{pH}$ was measured using a Beckmann $\Phi 50 \mathrm{pH} / \mathrm{ISE}$ Meter (Beckmann Instruments, Inc., Fullerton, CA) by direct immersion of a ROSS combination spear-tip $\mathrm{pH}$ electrode (Orion Research, Inc., Beverly, MA) into a finely ground cheese sample at ambient temperature. The TA was determined using the method described by Yun et al. (1993). Lactic acid contents $[\mathrm{L}(+)$ and $\mathrm{D}(-)]$ of cheese samples were determined by a colorimetric method (test kit no. 
11112821035; Boehringer Mannheim/R-Biopharm AG, Darmstadt, Germany).

The total lactic acid content of the crystalline material was determined by HPLC (VP Series, Shimadzu Corporation, Kyoto, Japan). Components for HPLC included SIL-10ADvp robotic auto-injector, LC-10ATvp solvent delivery unit, SPD-10Av UV detector, and 32bit CLASS-VP(R) software for data processing. The analysis was performed at $40^{\circ} \mathrm{C}$ at a flow rate of $1 \mathrm{~mL} /$ min using a $150 \times 4.66 \mathrm{~mm}$ Prevail organic acid column (Alltech, Deerfield, IL). The mobile phase used was 25 $\mathrm{m} M \mathrm{KH}_{2} \mathrm{PO}_{4}(\mathrm{pH} 2.5)$ and the detection was made at $210 \mathrm{~nm}$. The samples were prepared by the method described by Bouzas et al. (1991) with the following

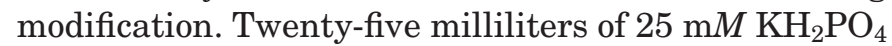
(mobile phase) was added to a 0.25 -g sample and extracted for $1 \mathrm{~h}$ with a magnetic stirrer. The extract was centrifuged (Sorvall Instruments, Wilmington, DE) at $5000 \times g$ for $10 \mathrm{~min}$. The supernatant was filtered through Whatman No. 1 filter paper (Whatman International Ltd., Maidstone, UK) and through a $0.2-\mu \mathrm{m}$ syringe filter (Fisherbrand, Cork, Ireland) and injected into the system. Duplicate analyses were performed for all samples. The concentrations of lactic acid in the samples were obtained by comparing peak areas of samples with those of standard lactic acid solutions (Alltech).

The $\mathrm{L}(+)$ and $\mathrm{D}(-)$ lactic acid content was also determined for one of the crystalline samples using the colorimetric method with the following modification. The crystalline material $(0.1 \mathrm{~g})$ was weighed into a 250 $\mathrm{mL}$ volumetric flask and $200 \mathrm{~mL}$ of distilled water was added and heated for $15 \mathrm{~min}$ at $60^{\circ} \mathrm{C}$ with occasional shaking. The solution was cooled to $25^{\circ} \mathrm{C}$ and water was added to $250 \mathrm{~mL}$. The flask was stored at $4^{\circ} \mathrm{C}$ for $15 \mathrm{~min}$ and the contents were filtered using Whatman No.1 filter paper (Whatman). The clear filtrate $(0.1 \mathrm{~mL})$ was used for the assay. The crystalline material was also analyzed for moisture content by drying in a forceddraft oven at $100^{\circ} \mathrm{C}$ for $24 \mathrm{~h} ; \mathrm{Ca}, \mathrm{P}$, and $\mathrm{Na}$ contents by inductively coupled plasma atomic emission spectrometry; and CP content (calculated as percentage total $\mathrm{N} \times 6.38$ ) by the Kjeldahl method, using a semimicro block digestion method (International Dairy Federation, 1993).

\section{Statistical Analyses}

The data for cheese composition were analyzed by ANOVA according to a repeated measures design with 2 within-subject variables using SuperAnova software (Abacus Concepts, Inc., Berkeley, CA). The cheese vats from which pairs of crystallized and noncrystallized samples originated were considered subjects. The
Table 1. Average composition of crystals that were collected from the surfaces of naturally smoked Cheddar cheese samples $(n=6)$.

\begin{tabular}{lcl}
\hline Component, \% & Mean & SD \\
\hline Calcium & 8.1 & 0.63 \\
Total lactic acid $^{1}$ & 52.1 & 7.16 \\
D(-) Lactate & 0 & - \\
Water & 28.5 & 5.67 \\
Phosphorus & 0.17 & 0.09 \\
NaCl & 1.56 & 0.35 \\
CP & 8.9 & 2.30 \\
\hline
\end{tabular}

${ }^{1} \mathrm{n}=1$.

within-subject variables were type of cheese surface (crystallized, noncrystallized) and depth from the cheese surface ( 0 to $5 \mathrm{~mm}, 6$ to $10 \mathrm{~mm}$, and greater than $10 \mathrm{~mm}$ ). Significance was determined at the 0.05 level of probability.

\section{RESULTS AND DISCUSSION}

\section{Composition of Surface Crystals}

The smoked cheese samples were stored for an additional 5 to 13 mo after collection to assure that the noncrystallized samples remained crystal free. By the end of this extended storage, the crystallized samples showed heavy coverage of irregularly shaped and distributed white crystalline regions that were assumed to be calcium lactate crystals. Average composition of the crystals that were collected from the surfaces of the crystallized cheese samples is shown in Table 1 . The crystalline material contained an average of $8.1 \% \mathrm{Ca}$, $52.1 \%$ total lactic acid, and $28.5 \%$ water. The enzymatic assay of $\mathrm{L}(+)$ and $\mathrm{D}(-)$ lactic acid for one of the samples showed the absence of $\mathrm{D}(-)$ lactic acid. Crystals collected from 5 other cheese samples produced at the same plant but not included in the present study also consisted exclusively of $\mathrm{L}(+)$ lactate (data not shown). The $\mathrm{P}$ content was only $0.17 \%$, which confirmed that the crystals were not composed of calcium phosphate. Assuming that all of the calcium was present as calcium lactate pentahydrate, the crystalline material contained $\sim 63 \%$ calcium lactate pentahydrate, plus about $10 \%$ free moisture and $16 \%$ free lactate. These values are in reasonable agreement with the compositional data reported by McDowall and McDowell (1939) and Farrer and Hollberg (1960) for surface crystals of calcium lactate obtained from Cheddar cheeses.

The crystalline material also contained $1.56 \% \mathrm{NaCl}$, which can be partly attributed to the $10 \%$ free water, presumably cheese serum, which was occluded in the crystals. However, the salt-in-moisture levels in the crystallized cheeses averaged only $4.05 \%$, therefore the 
Table 2. Mean squares (MS) and probabilities for compositional parameters of naturally smoked Cheddar cheese samples.

\begin{tabular}{|c|c|c|c|c|c|c|c|c|c|c|c|c|c|c|c|}
\hline \multirow[b]{2}{*}{ Factor } & \multirow[b]{2}{*}{ df } & \multicolumn{2}{|c|}{ Moisture } & \multicolumn{2}{|c|}{$\mathrm{NaCl}$} & \multicolumn{2}{|c|}{$\begin{array}{c}\text { Titratable } \\
\text { acidity }\end{array}$} & \multicolumn{2}{|c|}{$\mathrm{L}(+)$ Lactate } & \multicolumn{2}{|c|}{$\mathrm{pH}$} & \multicolumn{2}{|c|}{$\mathrm{WSC}^{1}$} & \multicolumn{2}{|c|}{ Total Ca } \\
\hline & & MS & $P$ & MS & $P$ & MS & $P$ & MS & $P$ & MS & $P$ & MS & $P$ & MS & $P$ \\
\hline Surface $^{3}(\mathbf{S})$ & 1 & $5.048^{*}$ & 0.03 & $0.442^{*}$ & $<0.01$ & $1.203^{*}$ & $<0.01$ & $0.391^{*}$ & $<0.01$ & $0.771^{*}$ & $<0.01$ & $1259.1^{*}$ & $<0.01$ & $1,193,556$ & 0.07 \\
\hline $\mathrm{S} \times$ Subject & 5 & 0.501 & & 0.010 & & 0.024 & & 0.011 & & 0.005 & & 39.2 & & 218,085 & \\
\hline $\operatorname{Depth}^{4}$ (D) & 2 & $4.209^{*}$ & $<0.01$ & $0.025^{*}$ & $<0.01$ & $0.017^{*}$ & 0.04 & 0.010 & 0.36 & 0.0001 & 0.67 & 19.8 & 0.56 & 31,500 & 0.83 \\
\hline $\mathrm{D} \times$ Subject & 10 & 0.079 & & 0.002 & & 0.004 & & 0.009 & & 0.0003 & & 37.3 & & 368,773 & \\
\hline
\end{tabular}

${ }^{1}$ Water-soluble Ca expressed as a percentage of total Ca.

${ }^{2}$ Cheese vats from which sample pairs originated.

${ }^{3}$ Surface characteristics of sample pairs: crystallized and noncrystallized.

${ }^{4}$ Depth from cheese surface: 0 to $5 \mathrm{~mm}, 6$ to $10 \mathrm{~mm}$, and $>10 \mathrm{~mm}$.

$* P<0.05$.

$10 \%$ serum presumably contributed only about $0.4 \%$ $\mathrm{NaCl}$ to the crystal mass, much lower that the $1.56 \%$ actually observed, for reasons that are not clear. Washam et al. (1985) also reported the presence of $\mathrm{NaCl}$ in calcium lactate crystals obtained from Cheddar cheese, and the depletion of $\mathrm{Na}$ and $\mathrm{Cl}$ ions in the cheese surface immediately below the crystal bloom. Finally, the crystalline material contained $8.9 \% \mathrm{CP}$, which may have been due to contamination by cheese that adhered to the crystals as they were dislodged and collected from the cheese surface, as reported by McDowall and McDowell (1939) and Washam et al. (1985). Alternatively, cocrystallization of tyrosine with calcium lactate may have contributed to the CP content. Harper et al. (1953) and Shock et al. (1948) reported that white surface crystals obtained from aged Cheddar cheeses contained not only calcium lactate but also tyrosine, the latter accounting for up to $36 \%$ of the crystals on a dry weight basis. However, it is important to note that the cheese samples analyzed by these researchers had been previously aged for extremely long periods (103 to $150 \mathrm{mo}$ ) and thus likely contained atypically high concentrations of free tyrosine due to extreme proteolysis. Cheese samples in the present study were much younger, ranging from 12 to 19 mo old at the time of analysis.

\section{Composition of Crystallized and Noncrystallized Cheeses}

Crystallized cheeses differed significantly from noncrystallized cheeses in levels of moisture, $\mathrm{NaCl}$, TA, $\mathrm{L}(+)$ lactate, $\mathrm{pH}$, and WSC expressed as a percentage of total calcium (Table 2). Furthermore, depth from the cheese surface significantly affected moisture, $\mathrm{NaCl}$, and TA contents (Table 2). The average moisture con- tents for crystallized and noncrystallized cheese samples at 3 different depths from the surface are compared in Figure 1. Crystallized cheeses contained significantly more moisture than noncrystallized cheese (Table 2). In addition, moisture content increased significantly with increasing depth from the surface for both crystallized and noncrystallized cheeses. However, the moisture gradient was larger for crystallized cheeses, resulting in a significant surface $\times$ depth interaction (Table 2). The observed gradients of moisture were probably caused by dehydration at the cheese surface during the smoking process (Washam et al., 1985), which, in turn, increased the concentrations of soluble components such as calcium and lactate ions in the

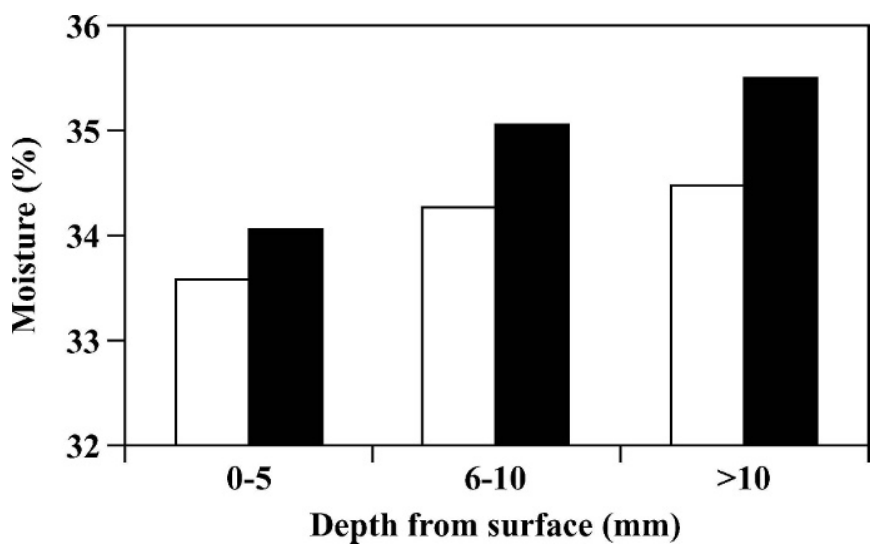

Figure 1. Average moisture content at 3 depths from the surfaces of 6 pairs of naturally smoked Cheddar cheese samples. Each sample pair included one crystallized and one noncrystallized sample that originated from the same vat of milk. Solid bars represent samples that developed surface crystals and open bars represent samples that remained crystal-free. 


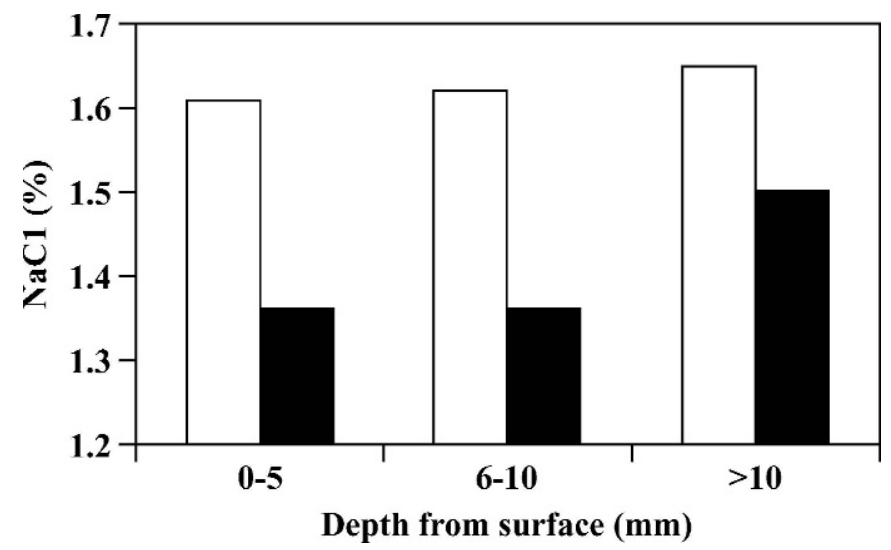

Figure 2. Average $\mathrm{NaCl}$ content at 3 depths from the surfaces of 6 pairs of naturally smoked Cheddar cheese samples. Each sample pair included one crystallized and one noncrystallized sample that originated from the same vat of milk. Solid bars represent samples that developed surface crystals and open bars represent samples that remained crystal-free.

water phase at the cheese surface.

The average $\mathrm{NaCl}$ contents for crystallized and noncrystallized cheese samples at 3 different depths from the surface are compared in Figure 2. Crystallized cheeses contained significantly less $\mathrm{NaCl}$ than noncrystallized cheese (Table 2). In addition, $\mathrm{NaCl}$ content showed a small but significant increasing trend with greater depth from the surface (Table 2). The lower salt content of crystallized samples compared with noncrystallized samples produced from the same vat (Figure 2) was probably caused by uneven salt application and uptake by the curd during manufacture. Large variation in salt content has been observed among commercial Cheddar cheeses manufactured from a single vat of milk (Fox, 1974; O'Connor, 1974), and even within individual blocks of cheese (O'Connor, 1973). Furthermore, it is well established that an inverse correlation exists between the $\mathrm{NaCl}$ and moisture contents in Cheddar cheese because whey expulsion during salting is directly related to the amount of salt added to and absorbed by the curd (Sutherland, 2003; Guinee and Fox, 2004). Thus, the observed differences in both $\mathrm{NaCl}$ and moisture contents within pairs of crystallized and noncrystallized cheese samples in the present study probably resulted from within-vat variation in salt application and, therefore, whey expulsion from the curd.

The average TA levels for crystallized and noncrystallized cheese samples at 3 different depths from the surface are compared in Figure 3. Crystallized samples contained significantly higher TA than noncrystallized samples (Table 2), indicative of higher lactic acid levels in the crystallized samples. Data presented in Figure 4 confirmed that $\mathrm{L}(+)$ lactate levels were significantly

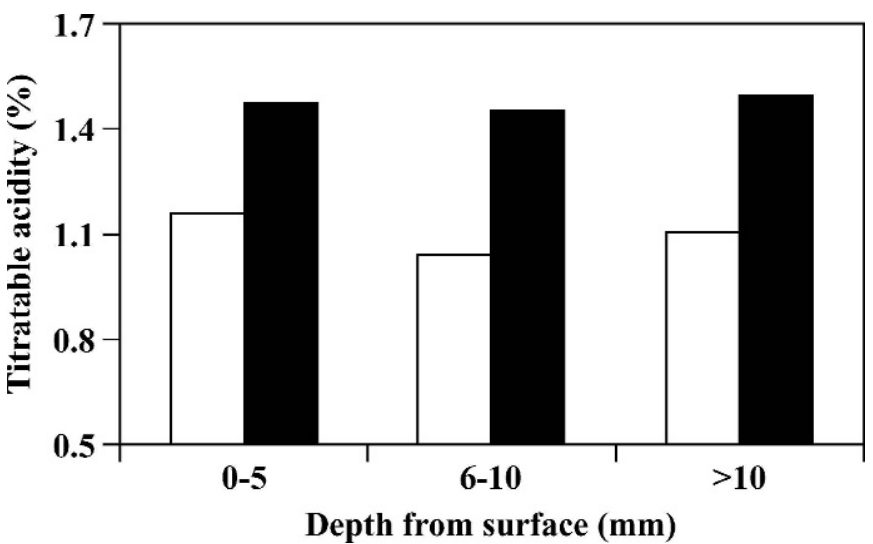

Figure 3. Average titratable acidity at 3 depths from the surfaces of 6 pairs of naturally smoked Cheddar cheese samples. Each sample pair included one crystallized and one noncrystallized sample that originated from the same vat of milk. Solid bars represent samples that developed surface crystals and open bars represent samples that remained crystal-free.

higher in crystallized cheeses (Table 2). It is also important to note that the lactate content of crystallized cheese samples was measured after the surface crystals were removed. The $\mathrm{L}(+)$ lactate contained within the surface crystals (Table 1) accounted for $18.54 \%$ of the total lactate originally present in the cheese samples on average. Therefore, concentrations of $\mathrm{L}(+)$ lactate originally present in the crystallized cheese samples before the start of crystallization were presumably about $19 \%$ higher than the measured values shown in Figure 4. Lower $\mathrm{L}(+)$ lactate content in noncrystallized samples was probably partly a direct result of their lower moisture content (Figure 1) and thus lower resid-

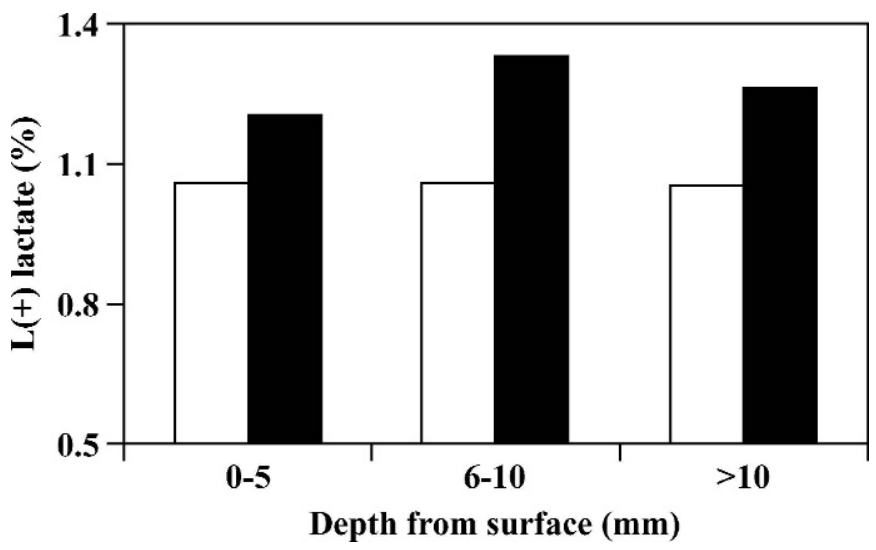

Figure 4. Average L(+) lactate content at 3 depths from the surfaces of 6 pairs of naturally smoked Cheddar cheese samples. Each sample pair included one crystallized and one noncrystallized sample that originated from the same vat of milk. Solid bars represent samples that developed surface crystals and open bars represent samples that remained crystal-free. 


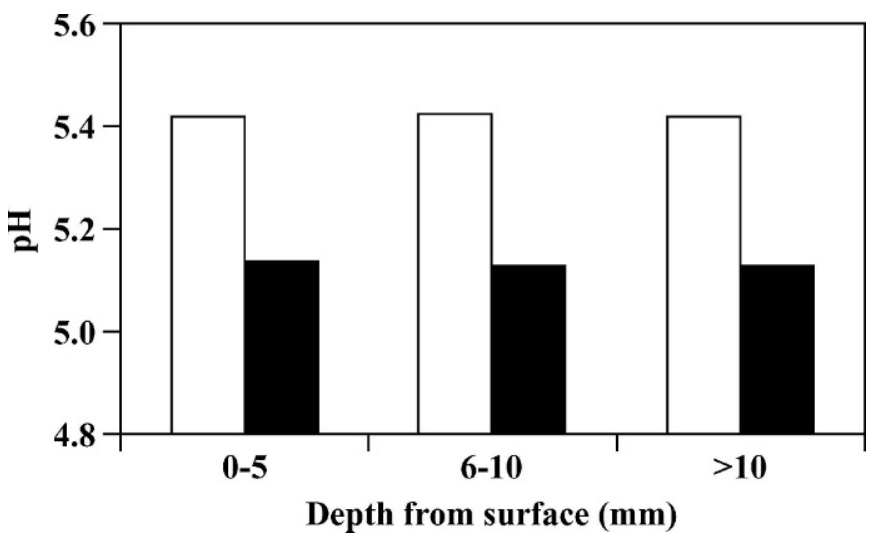

Figure 5. Average cheese $\mathrm{pH}$ at 3 depths from the surfaces of 6 pairs of naturally smoked Cheddar cheese samples. Each sample pair included one crystallized and one noncrystallized sample that originated from the same vat of milk. Solid bars represent samples that developed surface crystals and open bars represent samples that remained crystal-free.

ual lactose contained therein. Furthermore, higher saltin-moisture levels in noncrystallized $($ mean $=4.85 \%)$ compared with crystallized $($ mean $=4.05 \%)$ samples may have inhibited the complete fermentation of residual lactose by the starter culture, which could account for the low TA and lactate values of the noncrystallized samples. However, residual lactose was not measured in this study so firm conclusions cannot be drawn. No $\mathrm{D}(-)$ lactate was present in any of the cheese samples, nor in the crystalline material from the samples as mentioned previously. Therefore, racemization of $\mathrm{L}(+)$ to $\mathrm{D}(-)$ lactate by nonstarter lactic acid bacteria was not a factor in the development of calcium lactate surface crystals in the present study.

The average $\mathrm{pH}$ values for crystallized and noncrystallized cheese samples at 3 different depths from the surface are compared in Figure 5. The $\mathrm{pH}$ of crystallized samples was significantly lower than that of noncrystallized samples (Table 2), which was a direct consequence of the higher lactic acid concentrations in the former (Figure 4). Moreover, crystallized samples had significantly lower salt-in-moisture content (mean $=4.05 \%$ ), which would have favored more rapid fermentation of residual lactose in the cheese and a lower $\mathrm{pH}$ (Guinee and Fox, 2004). The lower $\mathrm{pH}$ of the crystallized samples would be expected to shift calcium from the insoluble to soluble states (Kindstedt et al., 2001; Ge et al., 2002; Swearingen et al., 2004). Such a shift occurred in the crystallized samples, as evidenced by significantly higher levels of WSC (Figure 6). Higher concentrations of soluble calcium combined with higher $\mathrm{L}(+)$ lactate levels (Figure 4) in the crystallized cheeses evidently caused the water phase at the cheese surface to become saturated, triggering crystallization. As a result, the

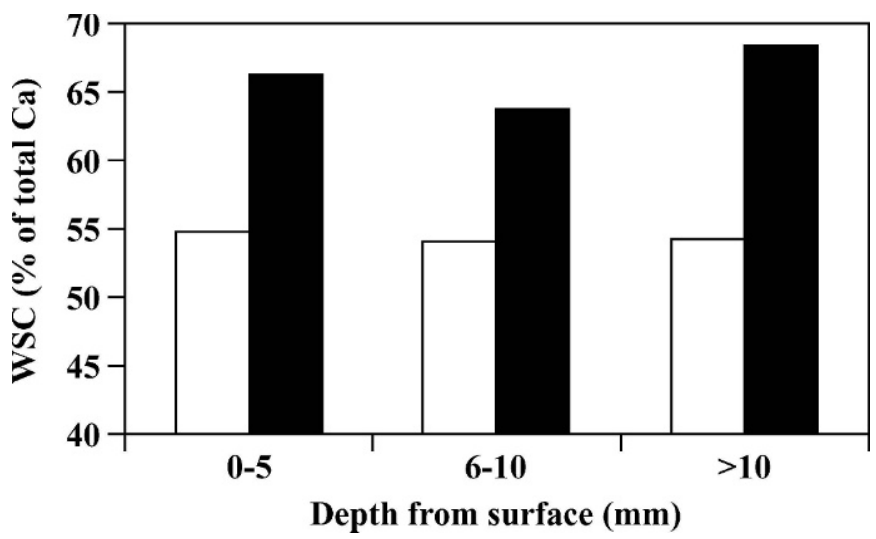

Figure 6. Average water-soluble Ca (WSC) content expressed as a percentage of total $\mathrm{Ca}$ at 3 depths from the surfaces of 6 pairs of naturally smoked Cheddar cheese samples. Each sample pair included one crystallized and one noncrystallized sample that originated from the same vat of milk. Solid bars represent samples that developed surface crystals and open bars represent samples that remained crystal-free.

interior of the cheese became progressively depleted of both calcium and lactate as crystallization proceeded. The calcium content of the surface crystals (Table 1) accounted for $6.3 \pm 1.3 \%$ of the total calcium originally present in the cheese samples. The average calcium contents for crystallized and noncrystallized cheese samples at 3 different depths from the surface are compared in Figure 7. Although not statistically significant $(P=0.07)$, the calcium content of crystallized samples (measured after the crystals were removed from the cheese surface) was about $6 \%$ lower on average than that of noncrystallized samples (Figure 7), which

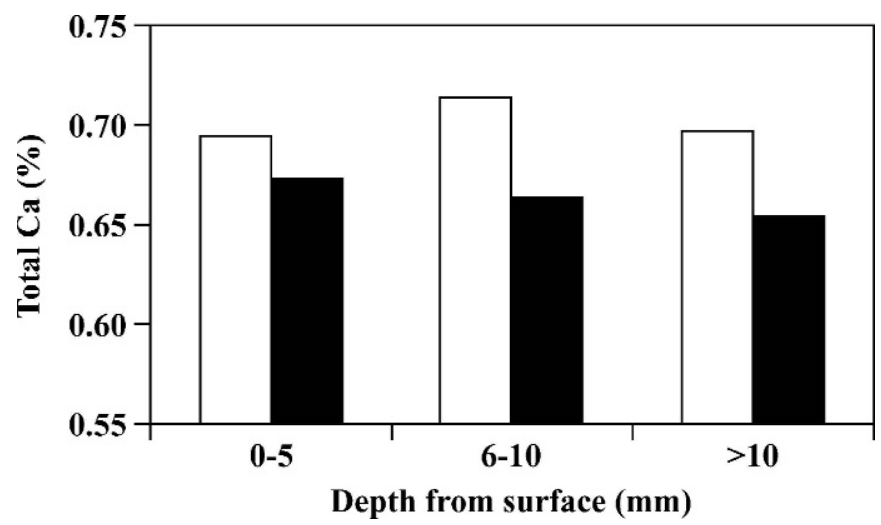

Figure 7. Average total Ca content at 3 depths from the surfaces of 6 pairs of naturally smoked Cheddar cheese samples. Each sample pair included one crystallized and one noncrystallized sample that originated from the same vat of milk. Solid bars represent samples that developed surface crystals and open bars represent samples that remained crystal-free. 
agreed with the calcium levels observed in the crystals (Table 1).

The results of this study indicated that the observed differences in crystallization behavior among cheese samples produced from the same vat were associated with compositional differences that were likely caused by uneven salting during manufacture. Dybing et al. (1988) also reported variation in crystallization behavior among cheese samples produced from the same vat. However, no significant differences in the salt and moisture contents of crystallized and noncrystallized cheeses were detected in that study. Indeed, the authors were unable to determine the causative factors for within-vat differences in crystallization behavior, which underscores the ongoing need to develop a better understanding of the many factors that influence calcium lactate crystallization.

\section{CONCLUSIONS}

Results of this study suggest that within-vat variation in salting efficacy was responsible for the observed differences in crystallization behavior among cheese samples produced from the same vat, according to the following scenario. Lower salt uptake and decreased whey expulsion by some of the curd during salting resulted in regions of lower salt and higher moisture within the final cheeses produced from that vat. Retailcut samples of the final cheese that contained lower salt and higher moisture contents also contained higher residual lactose, which caused more $\mathrm{L}(+)$ lactic acid to be produced in those samples. Higher lactic acid, in turn, resulted in lower cheese $\mathrm{pH}$, which caused a shift in calcium from the insoluble to the soluble state. Lactate and soluble calcium concentrations became further elevated at the cheese surface because of dehydration during smoking, thereby saturating the water phase and triggering crystallization. Conversely, samples that contained higher salt and lower moisture contents also contained less residual lactose, which may not have been fermented completely due to higher salt-in-moisture. This resulted in less $\mathrm{L}(+)$ lactic acid, higher cheese $\mathrm{pH}$, and less soluble calcium, which remained below threshold concentrations for calcium lactate crystallization.

\section{ACKNOWLEDGMENTS}

The financial support of the Northeast Dairy Foods Research Center and USDA Hatch Project VT-H01010 are gratefully acknowledged.

\section{REFERENCES}

Bouzas, J., C. A. Kantt, F. Bodyfelt, and J. A. Torres. 1991. Simultaneous determination of sugars and organic acids in Cheddar cheese in high-performance liquid chromatography. J. Food Sci. 56:276-278.

Chou, Y.-E., C. G. Edwards, L. O. Luedecke, M. P. Bates, and S. Clark. 2003. Nonstarter lactic acid bacteria and aging temperature affect calcium lactate crystallization in Cheddar cheese. J. Dairy Sci. 86:2516-2524.

Dybing, S. T., J. A. Wiegand, S. A. Brudvig, E. A. Huang, and R. C. Chandan. 1988. Effect of processing variables on the formation of calcium lactate crystals on Cheddar cheese. J. Dairy Sci. 71:1701-1710.

Farrer, K. T. H., and W. C. J. Hollberg. 1960. Calcium lactate on rindless cheese. Aust. J. Dairy Technol. 15:151-152.

Fox, P. F. 1974. Salt distribution in Cheddar cheese. Irish J. Agric. Res. 13:129-135.

Ge, Q., M. Almena-Aliste, and P. S. Kindstedt. 2002. Reversibility of $\mathrm{pH}$-induced changes in the calcium distribution and melting characteristics of Mozzarella cheese. Aust. J. Dairy Technol. 57:3-9.

Guinee, T. P., and P. F. Fox. 2004. Salt in cheese: Physical, Chemical and Biological Aspects. Page 207-259 in Cheese: Chemistry, Physics and Microbiology. 3rd ed. Vol 1. Elsevier Academic Press, London, UK.

Harper, W. J., A. M. Swanson, and H. H. Sommer. 1953. Observations on the chemical composition of white particles in several lots of Cheddar cheese. J. Dairy Sci. 36:368-372.

International Dairy Federation. 1993. Determination of nitrogen content. Provisional IDF Int. Stand. 20A:1993 Part 3. Int. Dairy Fed., Brussels, Belgium.

Johnson, M. E., B. A. Riesterer, C. Chen, B. Tricomi, and N. F. Olson. $1990 \mathrm{~b}$. Effect of packaging and storage conditions on calcium lactate crystallization on the surface of Cheddar cheese. J. Dairy Sci. 73:3033-3041.

Johnson, M. E., B. A. Riesterer, and N. F. Olson. 1990a. Influence of nonstarter bacteria on calcium lactate crystallization on the surface of Cheddar cheese. J. Dairy Sci. 73:1145-1149.

Kindstedt, P. S., A. Zielinski, M. Almena-Aliste, and C. Ge. 2001. A post-manufacture method to evaluate the effect of $\mathrm{pH}$ on Mozzarella cheese characteristics. Aust. J. Dairy Technol. 56:202-207.

Kubantseva, N., R. W. Hartel, and P. A. Swearingen. 2004. Factors affecting solubility of calcium lactate in aqueous solutions. J. Dairy Sci. 87:863-867.

McDowall, F. H., and A. K. R. McDowell. 1939. The white particles in mature Cheddar cheese. J. Dairy Res. 10:118-119.

Metzger, L. E., D. M. Barbano, and P. S. Kindstedt. 2001. Effect of milk preacidification on low fat Mozzarella cheese: III. Post-melt chewiness and whiteness. J. Dairy Sci. 84:1357-1366.

O'Connor, C. B. 1973. The quality and composition of Cheddar cheese: Effect of various rates of salt addition. Irish Agric. Cream. Rev. 26:5-7.

O'Connor, C. B. 1974. The quality and composition of Cheddar cheese: Effect of various rates of salt addition. Irish Agric. Cream. Rev. 27:11-13.

Pearce, K. N., L. K. Creamer, and J. Gilles. 1973. Calcium lactate deposits on rindless Cheddar cheese. N.Z. J. Dairy Sci. Technol. 8:3-7.

Shock, A. A., W. J. Harper, A. M. Swanson, and H. H. Sommer. 1948. What's in those "white specks" on Cheddar? Wisc Agr. Exp. Sta. Bull. 474. Univ. Wisconsin, Madison.

Somers, E. B., M. E. Johnson, and A. C. L. Wong. 2001. Biofilm formation and contamination of cheese by nonstarter lactic acid bacteria in the dairy environment. J. Dairy Sci. 84:1926-1936.

Sutherland, B. J. 2003. Cheese/Salting of Cheese. Page 293 in Encyclopedia of Dairy Sciences. Vol. 1. H. Roginski, J. W. Fuquay, and P. F. Fox, ed. Elsevier Science Ltd., London, UK.

Sutherland, B. J., and G. W. Jameson. 1981. Composition of hard cheese manufactured by ultrafiltration. Aust. J. Dairy Technol. 36:136-142.

Swearingen, P. A., D. E. Adams, and T. L. Lensmire. 2004. Factors affecting calcium lactate and liquid expulsion defects in Cheddar cheese. J. Dairy Sci. 87:574-582. 
Thomas, T. D., and V. L. Crow. 1983. Mechanism of D(-)-lactic acid formation in Cheddar cheese. N.Z. J. Dairy. Sci. Technol. 18:131-141.

Tuckey, S. L., H. A. Ruehe, and G. L. Clark. 1938. X-ray diffraction analysis of white specks in Cheddar cheese. J. Dairy Sci. $21: 161$. (Abstr.)

Washam, C. J., T. J. Kerr, and V. J. Hurst. 1982. Microstructure of various chemical compounds crystallized on Cheddar cheese. J. Food Prot. 45:594-596.
Washam, C. J., T. J. Kerr, V. J. Hurst, and W. E. Rigsby. 1985. A scanning electron microscopy study of crystalline structures on commercial cheese. Pages 749-761 in Developments in Industrial Microbiology. Vol. 26. Society for Industrial Microbiology, Arlington, VA.

Yun, J. J., D. M. Barbano, and P. S. Kindstedt. 1993. Mozzarella cheese: Impact of milling $\mathrm{pH}$ on chemical composition and proteolysis. J. Dairy Sci. 76:3629-3638. 